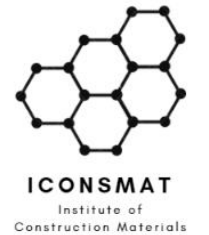

Content list available at ICONSMAT

Journal of Construction Materials

Journal homepage: www.iconsmat.com.au/publication
Article history:

Received 08 November 2020

Received in revised form

03 December 2020

Accepted 05 December 2020

Available online

2 January 2021

\title{
Preliminary structural design for extraterrestrial buildings
}

\author{
Farid Sartipi ${ }^{1 *}$ \\ 1* Corresponding author: E: farid.sartipi@iconsmat.com.au; Institute of Construction Materials
}

\begin{abstract}
The adventurous human nature had recently expanded to extraterrestrial habitation. Public billiondollar companies such as SpaceX and Blue Origin are investing extra ordinary capitals in space exploration. Australian Space Agency had also joined the space competition in 2018 in a so-called Mars mission. Although might sound far reaching, the idea of building human habitats on Mars requires well evaluated engineering design in the first stage as the cost of transporting equipment and materials as light as a kilogram to another planet is a massive financial burden. Throughout this passage, the effect of gravity, atmospheric pressure, and radiation on extra terrestrial buildings will be discussed. Following that a cylindrical structure as the most stable type of shell against internal pressure will be analyzed.
\end{abstract}

DOI: 10.36756/JCM.v2.2.3 @2020 Institute of Construction Materials

\section{(c) $(1)(8)$}

\section{Keywords}

Extraterrestrial construction; Structural analysis; 3D printing; Gravity; Air pressure 


\section{Introduction}

Engineering design process starts with identification of a need or a problem that must be addressed or solved. The engineer in the next step needs to cycle around the viable concepts and also evaluate each concept unit reach an optimized design. Thus, various concepts may be analyzed and compared [1]. In the context of human habitation on extraterrestrial planets, two popular building concepts are proposed (i) 3D printed structures using in situ materials; (ii) inflatable domes. To analyze these options, the engineer must acknowledge that a well-engineered extra-terrestrial structure demands consideration on the following criteria to be studied:

- The correlation between temperature cycles and structural and material fatigue,

- Structural sensitivity between different sections of a same component under internal and outer temperature gradient,

- Possibility of brittle fracture under the influence of extreme low temperature,

- The effect of vacuum on structural performance of building elements,

- Safety factors,

- Dead loads and live loads in a low gravity environment,

- Internally pressurized habitats and the stiffening, bracing, and buckling behaviours,

- Failure modes due to high velocity micrometeorite impacts.

It is important to note that although it is possible evaluate each of the above mentioned variable on earth, the combination of all these variables and their effect on the structural reliability is still in a limbo as it is difficult to, for example, creating a low gravity vacuum condition with a super low temperature environment on Earth, setting the experimental instrumentation aside. The engineering design process also requires design for service life and after life (recycling) which is beyond the scope of this research. To avoid the complexity, in this article the following three factors will be considered upon the structural design evaluation.

\section{Gravity}

Extra-terrestrial structures are subject to a fraction of gravity that they conventionally experience on earth. This will affect the bearing strength required from the materials used in construction. Benaroya in his article recommends to develop a mass-based system of calculation in that essence to maximize the utility of concepts rather than the existing weight-based model for construction on Earth [2].

\section{Internal air pressure}

A life-supporting close environment requires an internal air pressure level as on Earth. Apart from the design for bearing the internal pressure, the so-called design to fail-safe against catastrophic decompressions caused by accidental and natural impacts also needs to be considered.

\section{Shielding}

Buildings on other planets are subject to enormous level of solar radiation which is harmful for human being. It is closely dependent on the type of material used in the structure, yet the use of in situ materials to cover the whole building is once again advantageous in that regards. The thickness of the walls, as another factor, determines the penetration depth of the solar radiations. The designer must consider artificial lighting if soil is chosen as the shield against the solar/cosmic radiations. Reches studied the required thickness to protect the inhabitants from harmful radiations [3]. It is calculated 
that in order to completely stop the protons from penetration into the building, a 7-10 m thick concrete wall is required, which is impractical indeed. Although in the same article it is stated that a $6 \mathrm{~m}$ loose Martian regolith, if piled over the structure, can protect the human from radiations. The contradiction arises when the density of concrete and loose Martian regolith is compared as more energy lose is expected from a ray in a dense material than in a loose material. The formulation is given in the same article which is encouraged to enthusiasts.

\section{Construction Technology}

There have been many technologies proposed by the researchers in the past several years such as inflatable domes, erectable frames, precast concrete panels, and recently additive manufacturing. Out of all and after some assessments inflatable domes and additive manufacturing had shown promising results in providing extraterrestrial human shelter which are being discussed in this article.

\section{Additive manufacturing}

Researchers believe that robotics and additive manufacturing technologies have matured enough to be considered as a viable method of construction for space colonization. Yet, the complexity of components fabrication is an ongoing challenge that needs to be addressed. The fabrication of in situ materials is important as the extraterrestrial building is ought to protect life from the hostile and extreme environments. Bert [4] proposes the combination of biotechnology with fabricated structure which can produce a protective, self-healing and self-regulating system. Intelligent structures as such require embedded sensors and processors to constantly monitor the performance of the building [5].

Sintering, in general, as a promising fabrication method refers to the melting of the porous in situ material right below its melting point to enable the particles to bon together with a concurrent reduce in the volume and increase in density [6]. Some researchers had investigated the potential of sintering lunar regolith by using high powered laser, solar concentrator, or microwave energies. McKay et al. [7] states that mechanical sieving of particles might precedes the sintering.

Laser sintering had been investigated in few studies [8-10]. Yet, there are major drawbacks to this method of fabrication. First, the total energy required to melt a practical amount of material for construction is extremely high e.g. requiring nuclear power source. Another downturn of laser sintering is that only a small volume of material can be thermally treated at a time. Also, depositing hot melted regolith on a freezing surface encounters structural and mechanical problem. Solar sintering is, furthermore, considered as another alternative fabrication method. It has some advantageous over laser sintering as the solar energy is unlimited and readily available, although there might come subsequent site considerations as well i.e. how many hours the construction site is exposed to the solar radiation. From the disadvantages of solar sintering can be referred to as the depth of penetration of heat. It is reported that solar sintering has the penetration depth of maximum $6 \mathrm{~mm}[11,12]$.

\section{Inflatable domes}

M. Cohen in his article [13] classifies the extraterrestrial structures in to 3 different categories and states that prefabricated inflatable structures is suitable for 'settlement'. He considers three mission types as exploration, settlement, and colonization. In fact, this method of shelter has two main benefits compared to other methods being, first, that it has a lower carriage weight and second, once constructed, the habitable volume under cover is much larger than in other techniques. 
Kozicki proposed a detailed architectural design in 2011 [14] which appears to be a luxurious residential habitat. He had considered separated dining rooms, toilets, and kitchen. In logical terms, these types of designs are super futuristic due to the current limitations. Nevertheless, it is the same imagination that drives advancing nations.

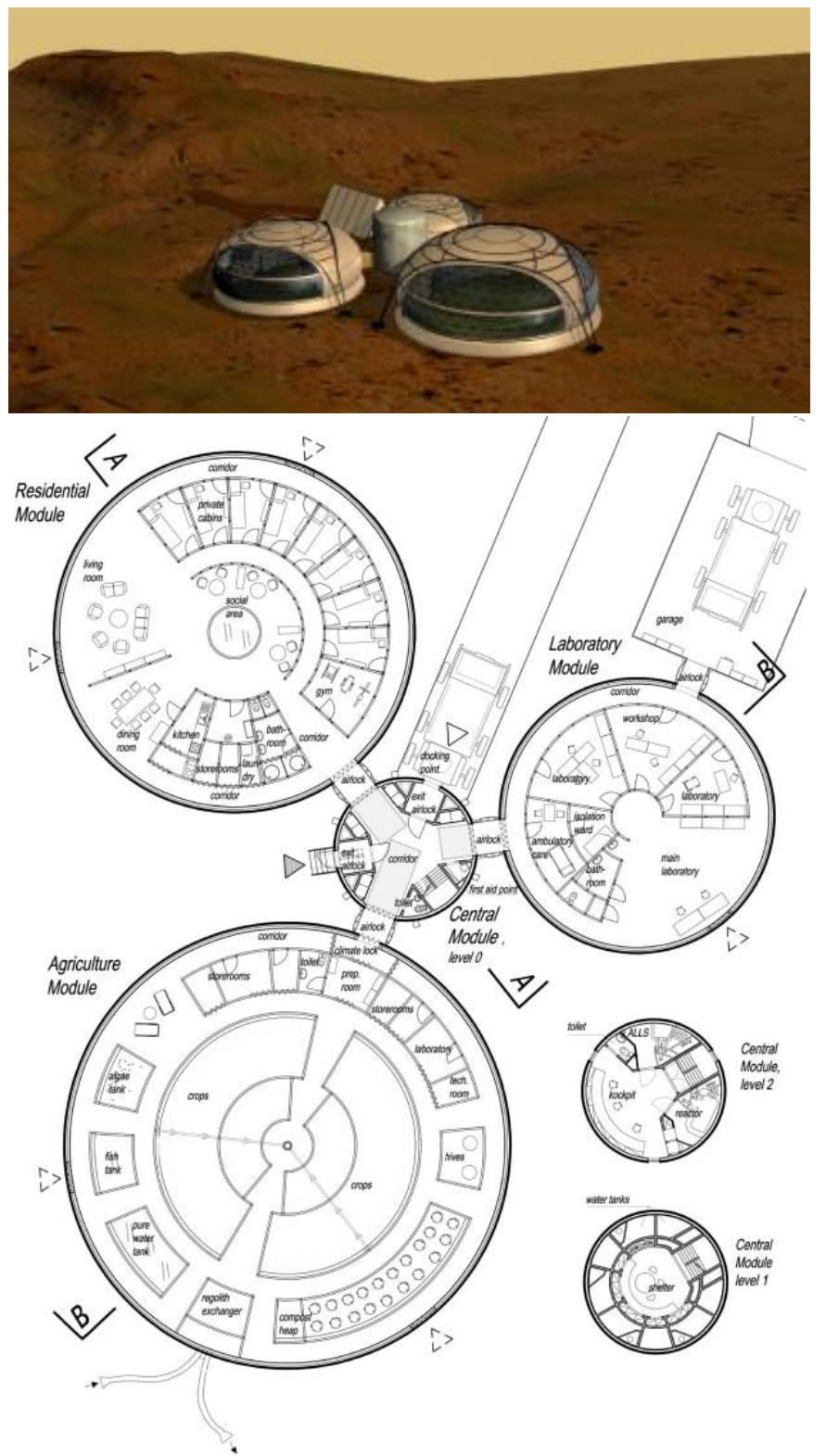

Figure 1 - Luxurious inflatable domes architectural design and specification [14].

\section{Structural Design Evaluation}

Regardless of the technology of construction, structural design of extraterrestrial habitats must satisfy criteria for gravity and internal pressure. In the following, 3D printing is selected for analysis because of its advantages over other alternatives. 


\section{Material properties}

Gebhardt et al. [15] had evaluated the properties of lunar regolith for in situ applications using laser sintering technique. The energy absorption of particles in laser sintering is highly reliant on the particle size. Therefore, for better results the homogeneity of size distribution is highly recommended in this method. The soil simulant from two previous missions to Mars is consist of the following portions [16, 17] :

Table 1 - Mineralogy of the Martian soil (\%)

\begin{tabular}{|c|c|c|c|c|c|c|c|c|c|c|}
\hline \multicolumn{2}{|c}{$\mathrm{Na}_{2} \mathrm{O}$} & $\mathrm{MgO}$ & $\mathrm{Al}_{2} \mathrm{O}_{3}$ & $\mathrm{SiO}_{2}$ & $\mathrm{SO}_{3}$ & $\mathrm{Cl}$ & $\mathrm{K}_{2} \mathrm{O}$ & $\mathrm{CaO}$ & $\mathrm{TiO}_{2}$ & $\mathrm{Fe}_{2} \mathrm{O}_{3}$ \\
\hline Pathfinder & 2.2 & 7.5 & 8.3 & 48.6 & 5.4 & 0.6 & 0.3 & 6.3 & 1.1 & 17.5 \\
\hline Viking & - & 6.0 & 7.2 & 43.4 & 7.4 & 0.8 & - & 5.8 & 0.6 & 18.2 \\
\hline
\end{tabular}

Concrete-alike materials are known as the feed in 3D printing construction technique. Reches [3] evaluates the options available to build concrete structures on Mars. Plaster of Paris (PoP), Ordinary Portland Cement, Alkali-activated cement, Geopolymer cement, Mg- and Si-based binders, and elemental sulfur are suggested as binder material. The origins to source these materials on Mars and the synthesis process are also discussed in his article.

Plaster of Paris $\left(\mathrm{CaSO}_{4} \cdot 1 /{ }_{2} \mathrm{H}_{2} \mathrm{O}\right)$ is a promising material for $3 \mathrm{D}$ printing construction on Mars $[18,19]$ that is made from calcining of gypsum $\left(\mathrm{CaSO}_{4} \cdot 2 \mathrm{H}_{2} \mathrm{O}\right)$. Bassanite, the naturally occurring $\mathrm{CaSO}_{4} \cdot 1 / 2 \mathrm{H}_{2} \mathrm{O}$, is also found in a number of locations on Mars [20].

\section{Design for gravity}

There are two major sub-considerations in designing extraterrestrial structures for gravity. First, it might become the case in low rise buildings that due to the inadequate amount of weight that it is carried down to the foundation, the structure may encounter a tension sum (due to the internal air pressure) instead of compression sum as opposed to the typical condition on earth. Second, since the gravity force is low in such environment, the building's footing and foundation (substructure) play an important role in the stability of the superstructure (what is built above the ground level).

Regarding the walls internal stress, on earth, the dead load generated by the mass of building materials used for construction gradually adds up from zero on the top to a certain amount on the ground level. Whereas in extraterrestrial structures, it might eb the case that at some point of the height, the sum of stresses turns towards a net tension because of the internal air pressure. In fact, the point in which this shift from compression to tension happens is reliant on the unit density of the construction material used in the building. 

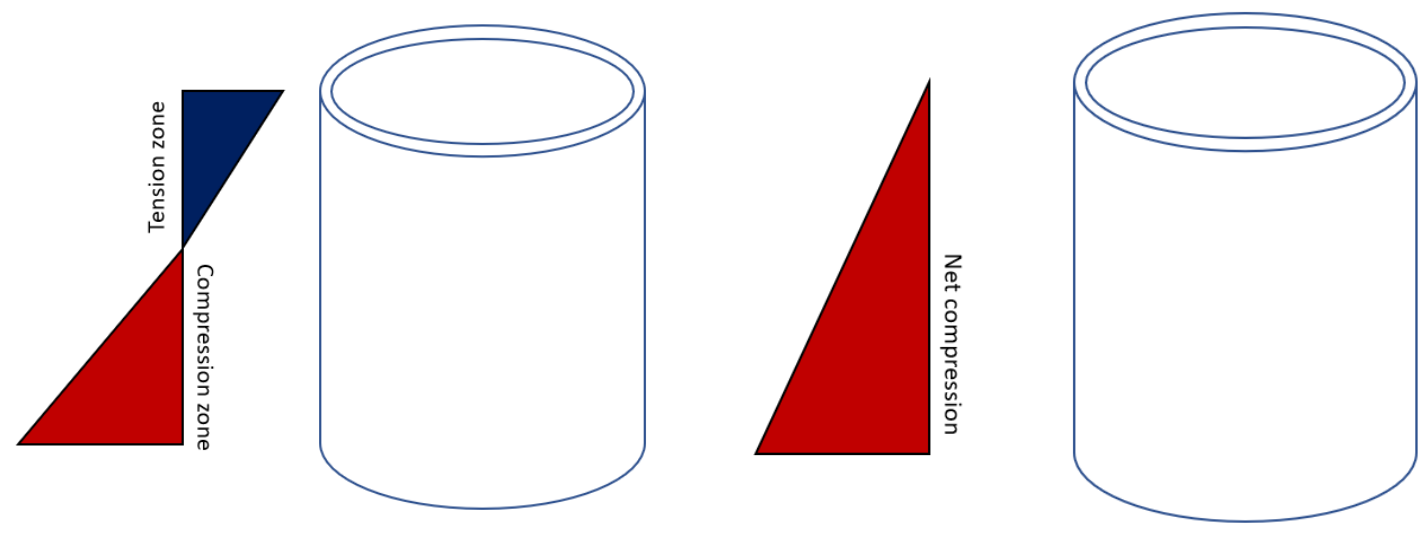

Figure 2 - Left: dead load distribution along the height of the building in extra-terrestrial structures; Right: Net compression as the dead load distribution along the height of the building on earth.

The substructure (footing and foundation) is responsible for the binding between superstructure and the ground underneath. It provides resistance against both vertical and horizontal displacements as a crucial factor in the sense of safety.

At any given distance from the top of the structure $(x)$ the weight of the structure is distributed over an area of $2 \pi r t$ where $r$ stands for internal radius and $t$ stands for the thickness of the wall. It is important to note the Martian constant of gravity $\left(\mathrm{g}_{\mathrm{m}}\right)$ in calculating the weight of the material used to build the structure:

$\sigma=\frac{F}{A}=\frac{x \cdot 2 \pi r \cdot t \cdot \rho \cdot g_{m}}{2 \pi r \cdot t}=x \cdot \rho \cdot g_{m}$

\section{Design for internal pressure}

At this point of design process, the building must be considered as a pressure vessel i.e. the design process for pressure vessels are adopted. Two types of stresses are applied to a given element on the shell: circumferential and longitudinal.

Assuming a cylindrical building which compromises the most uniform distribution of stress (since it doesn't have sharp points), the circumferential analysis on section A is as followed.
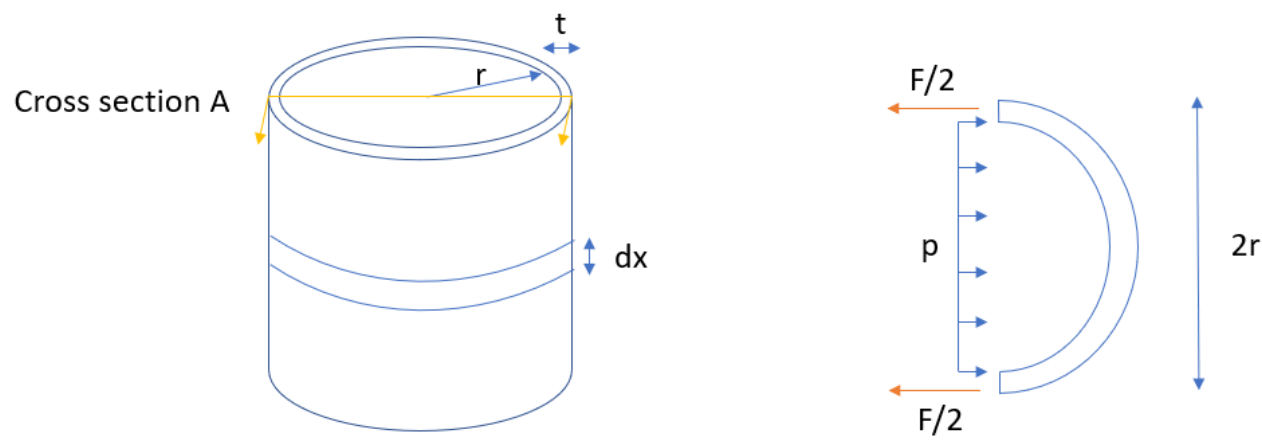

Figure 3 - Cross sectional analysis for circumferential stress 
$\sum F_{x}=0: p(2 r) d x-2\left(\frac{F}{2}\right)=0$

$F=2 p r d x$

$A=2 t d x$

By substituting (1) and (2) in $\sigma=F / A$ :

$$
\sigma_{1}=\frac{2 p r d x}{2 t d x}=\frac{p r}{t}
$$

For longitudinal stress analysis, the equilibrium between the internal air pressure and the shell resistance in cross section $B$ must be calculated:
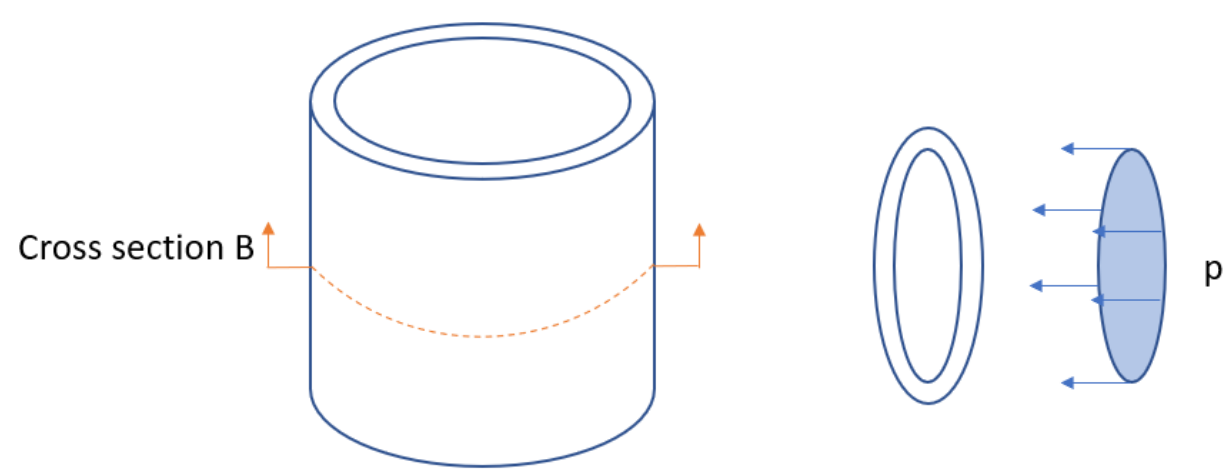

Figure 4 - Cross sectional analysis for longitudinal stress

Pressure force $=p(\pi) r^{2}$

Resisitng force of shell $=\sigma_{2} A=\sigma_{2}(2 \pi r) t$

After making the above equations equal:

$$
\begin{gathered}
p(\pi) r^{2}=\sigma_{2}(2 \pi r) t \\
\sigma_{2}=\frac{p r}{2 t}
\end{gathered}
$$

Thus, the circumferential stress is as twice as the longitudinal stress and therefore the walls must be designed based on this critical stress value. The parametric calculations above gives freedom of design to the architects to add complexity if desired.

Combining equation (1) and (4) the point at which the tension and compression even along the height is derived by the following equation (5): 
$x=\frac{p r}{2 t \cdot \rho \cdot g_{m}}$

The thickness of the walls ( $t$ ) in equation 5 must be calculated dependent upon external environmental variables such as temperature, radiation, and micrometeoric impacts. Using MATLAB 3D plot function, the graph of the equation 5 is roughly as shown in figure 5.

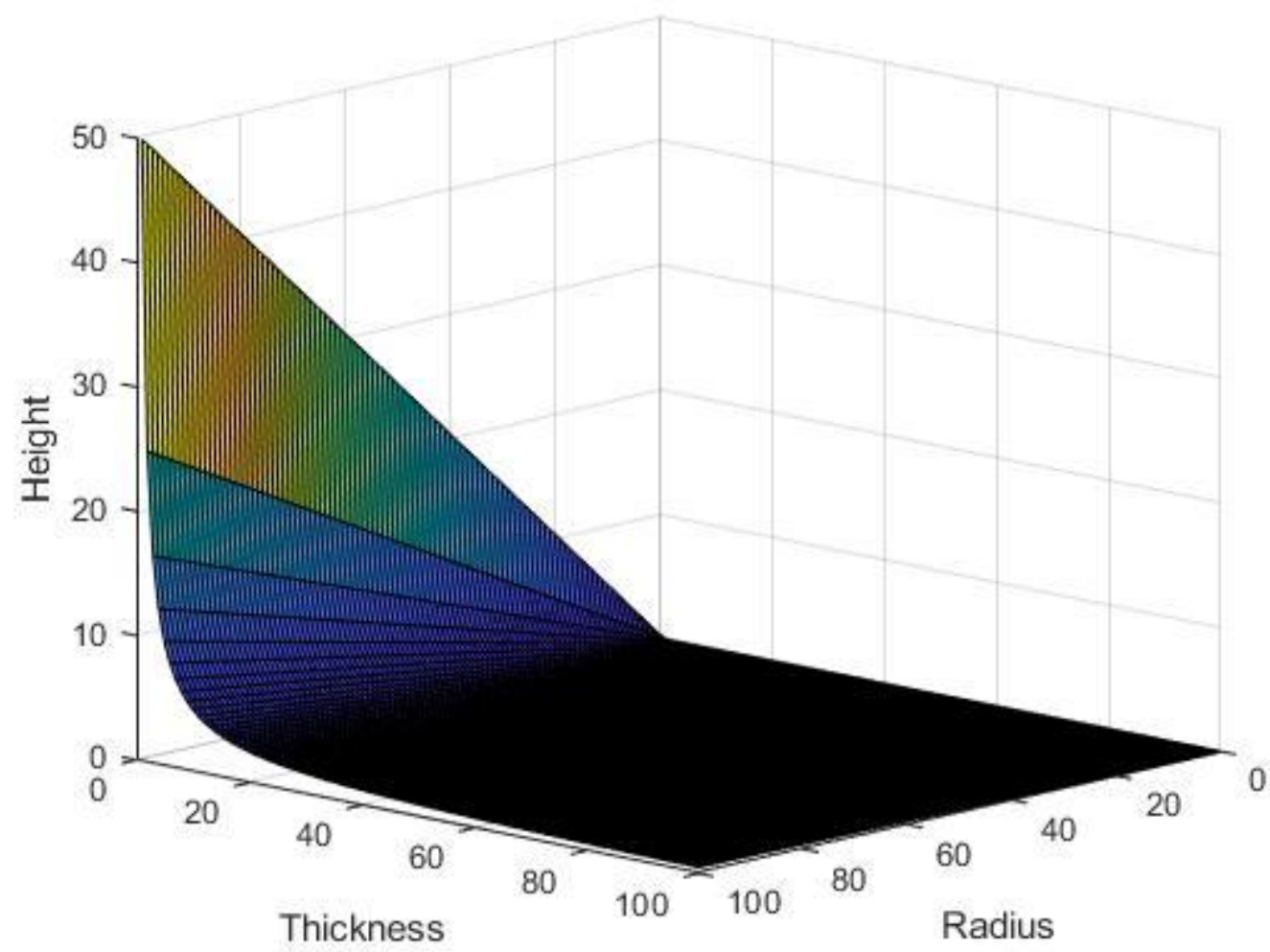

Figure 5 - Correlation of building's height, internal radius, and the thickness of the wall (Equation 5). Internal air pressure, density of the material and constant of gravity had been assumed to be 1 for simplification purposes.

\section{Calculating the required wall thickness}

The model of Chen and Li [21] for the projectile impact on concrete surface is adopted in this part of the study. It is the first-order estimate of the destructive power of micrometeorites.

$I=\frac{M \cdot v^{2}}{d^{3} \cdot f_{C} \cdot A \cdot N_{1}}$

$A=72 f_{c}^{0.5}$

$t_{1}=\frac{1}{2} d . I$

Where $\mathrm{M}$ is the mass of the micrometeorite $(\mathrm{kg}), \mathrm{v}$ is the impact velocity of the micrometeorite $(\mathrm{m} / \mathrm{s})$, $d$ is the dimension of the micrometeorite $(m), f_{c}$ is the compressive strength of the extrusion material 
(conventionally concrete), $\mathrm{N}_{1}$ is the nondimensional shape constant of the micrometeorite, and $\mathrm{t}_{1}$ is the penetration depth of impact into the wall $(\mathrm{m})$. The required thickness of the wall to avoid structural failure against the projectile impact is thus derived from the equation 8.

To evaluate the thickness of the wall required to resist the thermal gradient inside and outside of the building the principles of thermodynamics for the steady flow of heat are adopted.

$q=K \frac{\Delta T}{\Delta x}$

Where $\Delta x$ is equivalent to $t_{2}(\mathrm{~m})$ for the thickness of the wall by considering temperature as the main variable. $\mathrm{q}$ is the heat flux $\left(\mathrm{W} / \mathrm{m}^{2}\right), \mathrm{K}$ is the thermal conductivity $(\mathrm{W} / \mathrm{mK})$, and $\Delta T$ is the temperature differential. After finding $t_{1}$ and $t_{2}$ the thickness of the wall is determined by max $\left\{t_{1}, t_{2}\right\}$.

3D printed cylinders for housing are better designed longitudinally rather than flat by considering the above steps. This is because wide cylinders compromise a vast roof structure which imposes huge mechanical stress on the middle of the span. One might propose the use of columns in areas where the horizontal element is expanded wide. Yet, it must also be considered to design the column oddly for tension rather than compression in extra-terrestrial buildings since the internal air pressure is prevalent to gravity. Other relevant areas of study such as $\mathrm{CO}_{2}$ capture, digital technologies in construction, and graphene particularly in the sense of solar energy generation, are useful in the context of extraterrestrial construction [16, 22-33].

\section{Acknowledgement}

This study is motivated by One Giant Leap Australia Foundation as part of a research and development collaboration.

\section{Conclusion}

Several construction technologies had been proposed during the past couple of decades. In this study, however, two of the most viable technologies had been selected and discussed. 3D printing in priority to inflatable structures, demands preliminary structural evaluation for extraterrestrial applications. To avoid complexity in this preliminary study, gravity, atmospheric pressure, and radiation are chosen as the benchmark criteria, although many other factors are affecting the building performance on other planets. The mineralogy of Martian soil had been extracted from the existing literature to outline a basic understanding the properties if in situ material. Since the structure is subject to a massive internal pressure, the design for pressure vessels had been adopted in this study. Both circumferential and longitudinal stress analysis had been conducted. It had been identified, afterwards, that circumferential stress is more critical than longitudinal in terms of magnitude, and thus, it must be considered as the design stress. 


\section{References}

[1] E. T. Plan and S. Khandani, "Engineering design process," 2005.

[2] H. Benaroya, "Reliability of structures for the Moon," Structural safety, vol. 15, no. 1-2, pp. 6784, 1994.

[3] Y. Reches, "Concrete on Mars: Options, challenges, and solutions for binder-based construction on the Red Planet," Cement and Concrete Composites, vol. 104, p. 103349, 2019.

[4] R. Bert, "Out of This World: The New Field of Space Architecture, edited by A. Scott Howe and Brent Sherwood. Reston, VA: American Institute of Aeronautics and Astronautics, Inc., 2009," Civil Engineering-ASCE, vol. 80, no. 6, pp. 74-75.

[5] S. Lim, V. L. Prabhu, M. Anand, and L. A. Taylor, "Extra-terrestrial construction processesAdvancements, opportunities and challenges," Advances in Space Research, vol. 60, no. 7, pp. 1413-1429, 2017.

[6] B. Pletka, "Processing of lunar basalt materials," rnes, p. 325, 1993.

[7] D. S. McKay et al., "The lunar regolith," in Lunar sourcebook, vol. 7: Citeseer, 1991, pp. 285356.

[8] V. K. Balla, L. B. Roberson, G. W. O'Connor, S. Trigwell, S. Bose, and A. Bandyopadhyay, "First demonstration on direct laser fabrication of lunar regolith parts," Rapid Prototyping Journal, 2012.

[9] M. Fateri and A. Gebhardt, "Process parameters development of selective laser melting of lunar regolith for on-site manufacturing applications," International Journal of Applied Ceramic Technology, vol. 12, no. 1, pp. 46-52, 2015.

[10] A. Goulas, J. G. Binner, R. A. Harris, and R. J. Friel, "Assessing extraterrestrial regolith material simulants for in-situ resource utilisation based 3D printing," Applied Materials Today, vol. 6, pp. 54-61, 2017.

[11] P. Hintze, J. Curran, and T. Back, "Lunar surface stabilization via sintering or the use of heat cured polymers," in 47th AIAA Aerospace Sciences Meeting including The New Horizons Forum and Aerospace Exposition, 2009, p. 1015.

[12] P. E. Hintze and S. Quintana, "Building a lunar or martian launch pad with in situ materials: recent laboratory and field studies," Journal of Aerospace Engineering, vol. 26, no. 1, pp. 134142, 2013.

[13] M. M. Cohen, "Selected precepts in lunar architecture," in 34th COSPAR scientific assembly, 2002.

[14] J. Kozicki and J. Kozicka, "Human friendly architectural design for a small Martian base," Advances in Space Research, vol. 48, no. 12, pp. 1997-2004, 2011.

[15] M. Fateri, A. Gebhardt, and M. Khosravi, "Experimental investigation of selective laser melting of lunar regolith for in-situ applications," in ASME International Mechanical Engineering Congress and Exposition, 2013, vol. 56185: American Society of Mechanical Engineers, p. V02AT02A008.

[16] F. Sartipi, K. Palaskar, A. Ergin, and U. Rajakaruna, "Viable construction technology for habitation on Mars: Fused Deposition Modelling," Journal of Construction Materials, vol. 1, no. 2, 2020.

[17] J. Bell et al., "Mineralogic and compositional properties of Martian soil and dust: Results from Mars Pathfinder," Journal of Geophysical Research: Planets, vol. 105, no. E1, pp. 1721-1755, 2000.

[18] D. Barker, G. Chamitoff, and G. James, "Resource utilization and site selection for a selfsufficient martian outpost," 1998.

[19] C. R. Stoker and C. Emmart, "Strategies for Mars: a guide to human exploration," smgh, vol. 86, 1996. 
[20] K. Robertson and D. Bish, "Constraints on the distribution of CaSO4 $\cdot \mathrm{nH} 2 \mathrm{O}$ phases on Mars and implications for their contribution to the hydrological cycle," Icarus, vol. 223, no. 1, pp. 407-417, 2013.

[21] X. Chen and Q. Li, "Deep penetration of a non-deformable projectile with different geometrical characteristics," International Journal of Impact Engineering, vol. 27, no. 6, pp. 619-637, 2002.

[22] A. Todhunter, M. Crowley, M. Gholamisheverini, and F. Sartipi, "Advanced technological implementation of construction and demolition waste recycling," Journal of Construction Materials, vol. 1, no. 1, 2019, doi: https://doi.org/10.36756/JCM.v1.1.3.

[23] F. Sartipi, "Automatic sorting of recycled aggregate using image processing and object detection," Journal of Construction Materials, vol. 1, pp. 3-3, 2020, doi: https://doi.org/10.36756/JCM.v1.2.1.

[24] T. Boulos, F. Sartipi, and K. Khoshaba, "Bibliometric analysis on the status quo of robotics in construction," Journal of Construction Materials, vol. 1, pp. 2-3, 2020.

[25] F. Sartipi, "A brief critical view on the carbon-conditioning of recycled aggregate using pressure chamber," Journal of Construction Materials, vol. 2, pp. 1-4, 2020, doi: https://doi.org/10.36756/JCM.v2.1.4.

[26] F. Sartipi and A. Sartipi, "Brief review on advancements in construction additive manufacturing," Journal of Construction Materials, vol. 1, pp. 2-4, 2020, doi: https://doi.org/10.36756/JCM.v1.2.4

[27] A. Gharizadeh, F. Sartipi, E. Ayoubi, and A. Severino, "The chemical reactor design configuration of $\mathrm{CO} 2$ concrete green solution," Journal of Construction Materials, vol. 1, pp. 25, 2020, doi: https://doi.org/10.36756/JCM.v1.2.5.

[28] F. Sartipi, "Diffusion of Innovation Theory in the Realm of Environmental Construction," Journal of Construction Materials, vol. 1, pp. 4-2, 2020, doi: https://doi.org/10.36756/JCM.v1.3.2.

[29] F. Sartipi, A. Ghari Zadeh, and M. Gamil, "Electrical resistance of graphene reinforced cement paste," Journal of Construction Materials, 2019.

[30] F. Sartipi, "Influence of $5 \mathrm{G}$ and IoT in construction and demolition waste recycling-conceptual smart city design," Journal of Construction Materials, vol. 1, pp. 4-1, 2020, doi: https://doi.org/10.36756/JCM.v1.4.1.

[31] M. Gamil, A. Ghari Zadeh, and F. Sartipi, "A review on graphene reinforced cement composite: technical approach for ecofriendly construction," Journal of Construction Materials, 2019.

[32] M. Sartipi and F. Sartipi, "Stormwater retention using pervious concrete pavement: Great Western Sydney case study," Case Studies in Construction Materials, vol. 11, p. e00274, 2019.

[33] A. Todhunter, M. Crowley, F. Sartipi, and K. Jegendran, "Use of the by-products of postcombustion carbon capture in concrete production: Australian case study," Journal of Construction Materials, vol. 1, no. 1, 2019, doi: https://doi.org/10.36756/JCM.v1.1.1. 